\title{
Watching sport on television, physical activity, and risk of obesity in older adults
}

Mark Hamer $^{1 *}$, Richard Weiler ${ }^{1,2}$ and Emmanuel Stamatakis ${ }^{1,3}$

\begin{abstract}
Background: Television (TV) viewing has been associated with obesity although the effects of specific TV content on health and other behaviours remains unknown. We examined the association between watching sport on TV, physical activity levels, and risk of obesity.

Methods: We studied 6,733 (aged 64.9 \pm 9.2 yrs) men and women from the English Longitudinal Study of Ageing, a prospective study of community dwelling older adults. Data were collected on self reported TV time and content, and physical activity. Nurses measured height and weight for the calculation of body mass index.

Results: On average, participants reported viewing TV for $5.3 \pm 4.1$ hours per day and $30.3 \%$ of the sample watched sport on TV at least twice a week. There was no association between watching sport and physical activity levels. Participants that watched sports every day were at higher risk of obesity [odds ratio $=1.39,95 \% \mathrm{Cl}, 1.15,1.68$ ) after adjustment for age, sex, smoking, alcohol, physical activity, total TV time, disability, and self-rated health.
\end{abstract}

Conclusions: Watching elite athletes may have no role in the promotion of physical activity in older adults, which has implications for staging large sporting events with physical activity legacy promises.

Keywords: Ageing, Epidemiology, Health promotion, Obesity, Physical activity, Sedentary

\section{Background}

Excessive amounts of sedentary behaviours, such as viewing television (TV), have been linked to a range of metabolic health risks [1-4], and TV time has been associated with BMI and waist circumference in older adults indepedently of physical activity participation [5]. Watching sport, whether on TV or live at a venue, predominantly involves a prolonged sedentary period, which has become more widespread with the introduction of all-seater stadiums in some sports [6]. Whilst the effects of specific TV content on behaviours remains unknown, food and beverage advertising are commonplace at major sporting events [7], which have been linked to eating habits and obesity [8]. It has, however, been suggested that watching sporting events, such as the Olympics, may inspire individuals to take up sports, become more physically active and justify staging of such events with physical activity legacy promises [9]. The aim of this study was to examine the association

\footnotetext{
* Correspondence: m.hamer@ucl.ac.uk

'Population Health Domain Physical Activity Research Group, Department of Epidemiology and Public Health, University College London, 1-19 Torrington Place, London WC1E 6BT, UK

Full list of author information is available at the end of the article
}

between watching sport on TV, physical activity levels, and risk of obesity in a representative sample of older adults from the UK.

\section{Methods \\ Participants and study design}

We studied 6,733 (aged 64.9 $\pm 9.2 \mathrm{yrs}$ ) men and women from the English Longitudinal Study of Ageing (ELSA), an ongoing cohort study that contains a nationally representative sample of the English population living in households [10]. The first wave of data was collected in 2002-03, although for the present study we used data collected at wave 4. (2008-09) when information on TV viewing was first gathered. Participants gave full informed written consent to participate in the study and ethical approval was obtained from the London Multi-centre Research Ethics Committee.

\section{TV viewing and physical activity}

Participants were asked to recall "How many hours of television do you watch on an ordinary day or evening, that is, Monday to Friday?" and "How many hours of television do you normally watch in total over the weekend, that is, 
Saturday and Sunday?" Average daily time spent watching TV was calculated as \{(weekday TV time x 5) + (Weekend TV time) $3 / 7$. Participants were also asked questions regarding TV content that was categorised as the frequency per week that they watched specific types of programmes : 'How often do you watch sports on TV'.

We have described the ELSA physical activity measurements in detail previously [11]. In brief, participants were asked how often they took part in three different types of physical activity: vigorous, moderate- and low-intensity physical activity. Before answering, participants were shown prompt cards to help them interpret different PA intensities. Examples of moderate intensity activity included gardening, cleaning the car, walking at moderate pace, dancing, and floor or stretching exercises; vigorous intensity included running/jogging, swimming, cycling, aerobics/gym workout, tennis, and digging with a spade. The response options were: more than once a week, once a week, one to three times a month and hardly ever/never. Physical activity was further categorized into a binary variable based on reporting moderate or vigorous activity more than once a week.

\section{Obesity}

Nurses collected anthropometric data (weight, height). Participants' body weight was measured using Tanita electronic scales without shoes and in light clothing, and height was measured using a Stadiometer with the Frankfort plane in the horizontal position. Body mass index (BMI) was calculated using the standard formulae [weight (kilograms)/ height (meters) squared]. Obesity was defined as BMI $\geq$ $30 \mathrm{~kg} / \mathrm{m}^{2}$.

\section{Covariates}

Demographic and health-related questions included cigarette smoking (current, previous or non-smoker), frequency of alcohol intake (daily, 5-6/wk, 3-4/wk, 1-2/wk, $1-2 /$ month, once every couple of months, 1-2/year, never), self rated health (excellent, very good, good, fair, poor) and disability. We assessed disability based on participants' responses to questions on perceived difficulties in basic (e.g., difficulty dressing, including putting on shoes and socks) [12] and instrumental (e.g., difficulty preparing a hot meal) activities of daily living (ADL) [13]. Participants with difficulties in one or more activities were considered to have some degree of disability.

\section{Statistical analysis}

We used $\chi^{2}$ (for categorical) and ANOVA tests (for continuous data) to examine differences in characteristics across sports TV viewing groups. We calculated odds ratios (OR) and 95\% confidence intervals (CI) for the risk of obesity in relation to viewing sport, which was categorized into three groups (once or less a week, twice or more a week, or daily). We adjusted the models for age, sex, cigarette smoking, alcohol intake, physical activity, selfrated health, disability, and total daily TV viewing $(<2 \mathrm{hrs} / \mathrm{d}$; 2 to $<4 \mathrm{hrs} / \mathrm{d}$; 4 to $<6 \mathrm{hrs} / \mathrm{d} ; \geq 6 \mathrm{hrs} / \mathrm{d}$ ). Modification by sex was explored by fitting a sex by sports viewing interaction term. In addition, we examined the association beween viewing sport on TV and physical activity using binary logistic regression with physical activity as the depedent variable (categorised into inactive or active based on participation of any moderate or vigorous activity more than once a week). All analyses were conducted using SPSS version 20 .

\section{Results}

On average, participants reported viewing TV for $5.3 \pm$ 4.1 hours per day and $30.3 \%$ of the sample watched sport on TV at least twice a week. Participants that viewed sport were more likely to be men, reported greater total TV viewing time, impairments in ADL/IADLs and rate their health as poor (Table 1). $69.9 \%$ of the sample reported participating in moderate or vigorous activity more than once a week and $21.6 \%$ of the sample were vigorously active more than once a week. There was no association between watching sport and physical activity levels ( -trend $=0.19$ ) ; in comparison with participants watching sport once or less a week, those that watched sport twice or more a week $(\mathrm{OR}=1.15,95 \% \mathrm{CI}, 0.98-1.34)$, or daily $(\mathrm{OR}=1.01$, $95 \%$ CI, 0.83 - 1.24) were no more likely to be active, after adjusting for age, sex, smoking, alcohol, total daily TV time, impairments in ADLs/IADLs, and self rated health. Similarly, when we used only vigorous activity as the dependent variable there was no association between watching sport and participation in vigorous activity ( $\mathrm{p}$-trend $=0.08$ ).

Obesity was prevalent in $30.8 \%$ of the sample. Watching sport on TV was associated with higher risk of obesity in a dose-response manner (Table 2), and these associations persisted after adjustment for covariates, including total TV viewing time and physical activity. The sex interaction term was significant $(\mathrm{p}=0.026)$, and sex stratified analysis showed that associations between daily sports viewing and obesity were evident in men (multivariable adjusted $\mathrm{OR}=1.57,95 \% \mathrm{CI}, 1.24-1.97)$ but not women $(\mathrm{OR}=$ $1.08,95 \% \mathrm{CI}, 0.75$ - 1.55). For each $2 \mathrm{hr} / \mathrm{d}$ increase in total TV viewing there was an incremental increase in obesity risk $(\mathrm{OR}=1.28,95 \% \mathrm{CI}, 1.21$ - 1.36) after adjusting for age, sex, smoking, alcohol, physical activity, impairments in ADLs/IADLs, and self-rated health.

\section{Discussion}

The main aim of this study was to examine the association between viewing sport on TV with physical activity levels and obesity. It is likely that greater numbers of people watch sport on TV than live at the venue and viewing TV is therefore a greater public health concern. Contrary to 
Table 1 Characteristics of the sample in relation to viewing sport on television

\begin{tabular}{|c|c|c|c|c|}
\hline \multirow[t]{2}{*}{ Variable } & \multicolumn{3}{|c|}{ Viewing sport on TV } & \multirow[t]{2}{*}{ p-value } \\
\hline & Once or less a week & Twice or more a week & Daily & \\
\hline Mean age (yrs) & $64.5 \pm 9.3$ & $65.7 \pm 9.1$ & $65.7 \pm 9.0$ & $<0.001$ \\
\hline Sex (\% men) & 36.3 & 68.9 & 77.0 & $<0.001$ \\
\hline Smoking (\%) & 12.7 & 9.8 & 13.4 & 0.007 \\
\hline Alcohol (\% at least 5/wk) & 22.7 & 27.9 & 23.3 & $<0.001$ \\
\hline Mean total TV viewing (hrs/d) & $5.0 \pm 4.0$ & $5.6 \pm 3.9$ & $6.8 \pm 4.9$ & $<0.001$ \\
\hline 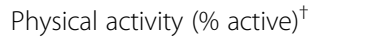 & 69.2 & 73.6 & 66.6 & 0.001 \\
\hline Impairements in ADL/IADLs & 23.2 & 20.5 & 26.4 & 0.001 \\
\hline Self rated health (\% poor) & 5.1 & 4.3 & 7.7 & 0.001 \\
\hline Mean body mass index $\left(\mathrm{kg} / \mathrm{m}^{2}\right)$ & $28.0 \pm 5.3$ & $28.5 \pm 5.0$ & $28.9 \pm 5.3$ & $<0.001$ \\
\hline
\end{tabular}

${ }^{\dagger}$ defined as moderate or vigorous activity more than once a week.

the assumption that watching sport on TV may be associated with greater uptake of physical activity, we found no evidence to support this hypothesis. In fact, more frequent watchers of sport on TV demonstrated the highest amount of daily time spent watching TV and a higher risk of being obese. The association between viewing sports on TV and obesity was particularly evident in men.

These findings have relevance for the promotion of physical activity to the general population, especially in light of current debate surrounding the justification for holding Olympic and major sporting events and health legacy pledges [14]. Although higher than average levels of sports participation were recorded in the late summer period of 2012, immediately after the Olympic Games, more recent data released from Sport England [15] suggests negligible differences in sports participation compared with the same period prior to the games. This is largely consistent with other evidence examining the impact of major sporting events on population physical activity levels and health [16,17]. Evidence suggests that uptake of physical activity is optimised in the presence of peer support or when peers are used as role models $[18,19]$. However, if the social norm and our true peer group are watching sport on $\mathrm{TV}$, rather than participating in sport, then lack of evident behavioural

Table 2 Watching sports on TV and risk of obesity in older adults $(n=6,733)$

\begin{tabular}{llll}
\hline $\begin{array}{l}\text { Frequency of viewing } \\
\text { sport on TV }\end{array}$ & Cases/N & $\begin{array}{l}\text { Model } \mathbf{1} \\
\text { OR }(\mathbf{9 5 \%} \mathbf{~ C l})\end{array}$ & $\begin{array}{l}\text { Model } \mathbf{2} \\
\text { OR }(\mathbf{9 5 \%} \mathbf{C I})\end{array}$ \\
\hline Once or less a week & $1387 / 4690$ & Reference & Reference \\
Twice or more a week & $443 / 1410$ & $1.21(1.06,1.38)$ & $1.17(1.01,1.35)$ \\
Daily & $242 / 633$ & $1.67(1.40,2.00)$ & $1.39(1.15,1.68)$ \\
P-trend & & $<0.001$ & 0.001 \\
\hline
\end{tabular}

Model 1 adjusted for age and sex.

Model 2 adjusted for age, sex, physical activity, smoking, alcohol, total daily TV time, impairments in ADLs/IADLs, self rated health. effect is completely understandable. Using peers as role models is also known to increase self efficacy, a key driver in the uptake of physical activity. Watching elite athletes may therefore have no role in the promotion of physical activity in older adults.

The association between viewing sport and obesity was independent of total TV viewing time, suggesting that other mechanisms might also partly explain the effects. One possibility is that participants consume more unhealthy foods and beverages whilst watching sports, which may in part be driven by sponsorship relationships between sporting organisations and food and beverage brands [7]. Indeed, experimental evidence has demonstrated that food advertising increased consumption of products not in the presented advertisements, and these effects were not related to reported hunger or other conscious influences [8]. Nevertheless, we were unable to adjust for dietary intake in our analysis. Our data are based on self-report that might have introduced bias, thus we cannot discount the possibility of residual confounding. We have, however, previously demonstrated the validity of measures such as self-reported morbidity in ELSA [20]. Physical activity was assessed crudely although the measure has demonstrated excellent convergent validity in grading a plethora of psychosocial, physical and biochemical risk factors [11,21]. Since these analyses were cross-sectional we cannot discount the possibility of reverse causation in that obesity and poorer general health causes people to spend more time sedentary and not the reverse. Indeed, a recent study in middle-aged and older adults demonstrated that BMI at baseline was prospectively associated with greater TV viewing at follow-up but not the converse [22]. Lastly, this study was restricted to older adults and we do not know if the same null associations between watching sport on TV and physical activity would be observed in younger adults who might more readily identify with their sport playing peer group. 


\section{Conclusions}

In conclusion, we found no association between watching sport on TV and physical activity levels in a representative sample of older adults. These data question using health legacy pledges as a vehicle to justify staging major sporting events.

\section{Abbreviations}

TV: Television; ELSA: English Longitudinal Study of Ageing; BMI: Body mass index; OR: Odds ratio; IADL: Instrumental activities of daily living;

ADL: Activities of daily living.

\section{Competing interests}

None of the authors have any competing interests to declare.

\section{Authors' contributions}

$\mathrm{MH}$ had full access to the data, and takes responsibility for the integrity and accuracy of the results. MH drafted the paper. All authors contributed to the concept and design of study, drafting and critical revision of the manuscript. All authors read and approved the final manuscript.

\section{Funding sources}

The data were made available through the UK Data Archive. The English Longitudinal Study of Ageing (ELSA) was developed by a team of researchers based at University College London, the Institute of Fiscal Studies and the National Centre for Social Research. The funding is provided by the National Institute on Aging in the United States (grants 2RO1AG7644-01A1 and 2RO1AG017644) and a consortium of UK government departments coordinated by the Office for National Statistics. MH is supported by the British Heart Foundation (RE/10/005/28296); ES is supported by a National Institute for Health Research Career Development award. The funders had no role in the study design; in the collection, analysis and interpretation of data; in writing of the report; or in the decision to submit the paper for publication. The developers and funders of ELSA and the Archive do not bear any responsibility for the analyses or interpretations presented here.

\section{Author details}

'Population Health Domain Physical Activity Research Group, Department of Epidemiology and Public Health, University College London, 1-19 Torrington Place, London WC1E 6BT, UK. ${ }^{2}$ University College London Hospitals NHS Foundation Trust, London, UK. ${ }^{3}$ Prevention Research Collaboration, School of Public Health, University of Sydney, Sydney, Australia.

Received: 27 September 2013 Accepted: 5 January 2014 Published: 8 January 2014

\section{References}

1. Edwardson CL, Gorely T, Davies MJ, Gray LJ, Khunti K, Wilmot EG, Yates T, Biddle SJ: Association of sedentary behaviour with metabolic syndrome: a meta-analysis. PLoS One 2012, 7(4):e34916.

2. Stamatakis E, Hamer M, Mishra G: Early adulthood TV viewing and cardiometabolic risk profiles in early middle age: results from a population, prospective cohort study. Diabetologia 2012, 55:311-320.

3. Stamatakis E, Hirani V, Rennie K: Moderate-to-vigorous physical activity and sedentary behaviours in relation to body mass index-defined and waist circumference-defined obesity. Br J Nutr 2009, 101:765-773.

4. Hu FB, Li TY, Colditz GA, Willett WC, Manson JE: Television watching and other sedentary behaviors in relation to risk of obesity and type 2 diabetes mellitus in women. JAMA 2003, 289:1785-1791.

5. Stamatakis E, Davis M, Stathi A, Hamer M: Associations between multiple indicators of objectively-measured and self-reported sedentary behaviour and cardiometabolic risk in older adults. Prev Med 2012, 54:82-87.

6. Fédération Internationale de Football: Safety regulations. http://www.fifa. com/mm/document/tournament/competition/51/53/98/safetyregulationse. pdf (accessed 2013 Dec 13).

7. Carter MA, Signal L, Edwards R, Hoek J, Maher A: Food, fizzy, and football: promoting unhealthy food and beverages through sport - a New Zealand case study. BMC Public Health 2013, 13:126.

8. Harris $J L$, Bargh $J A$, Brownell $K D$ : Priming effects of television food advertising on eating behavior. Health Psychol 2009, 28(4):404-413.
9. UK Government: Inspiring a generation: A Taking Part report on the 2012 Olympic and Paralympic Games. https://www.gov.uk/government/uploads/ system/uploads/attachment_data/file/78316/Taking_Part_Olympic_Report. pdf (accessed 2013 June 25).

10. ELSA user guide and documentation: UK Data Archive. http://www.data-archive. ac.uk/findingData/snDescription.asp?sn=5050 (accessed 2008 August 21).

11. Demakakos P, Hamer M, Stamatakis E, Steptoe A: Low-intensity physical activity is associated with reduced risk of incident type 2 diabetes in older adults: evidence from the english longitudinal study of ageing. Diabetologia 2010, 53:1877-1885.

12. Katz S, Downs TD, Cash HR: Progress in development of the index of ADL. Gerontologist 1970, 10:20-30.

13. Lawton MP, Brody EM: Assessment of older people: self-maintaining and instrumental activities of daily living. Gerontologist 1969, 9:179-186.

14. Weed M, Coren E, Fiore J, Wellard I, Mansfield L, Chatziefstathiou D, Dowse S: Developing a physical activity legacy from the London 2012 Olympic and Paralympic Games: a policy-led systematic review. Perspect Public Health 2012, 132(2):75-80.

15. Sport England: Sport participation factsheet: summary of results for England. Active people survey 7: April 2012 - April 2013. http://www.sportengland.org/research/ active_people_survey/active_people_survey_7.aspx (accessed 2013 June 19).

16. McCartney G, Thomas S, Thomson H, Scott J, Hamilton V, Hanlon P, Morrison DS, Bond $\mathrm{L}$ : The health and socioeconomic impacts of major multi-sport events: systematic review (1978-2008). BMJ 2010, 340:C2369.

17. Mahtani KR, Protheroe J, Slight SP, Demarzo MM, Blakeman T, Barton CA, Brijnath B, Roberts N: Can the London 2012 Olympics 'inspire a generation' to do more physical or sporting activities? An overview of systematic reviews. BMJ Open 2013, 3(1). doi: 10.1136/bmjopen-2012-002058.

18. Buman MP, Giacobbi PR Jr, Dzierzewski JM, Aiken Morgan A, McCrae CS, Roberts BL, Marsiske M: Peer volunteers improve long-term maintenance of physical activity with older adults: a randomized controlled trial. J Phys Act Health 2011, 8(Suppl 2):S257-S266.

19. Edmunds S, Stephenson D, Clow A: The effects of a physical activity intervention on employees in small and medium enterprises: a mixed methods study. Work 2012: [Epub ahead of print].

20. Pierce MB, Zaninotto P, Steel N, Mindell J: Undiagnosed diabetes-data from the english longitudinal study of ageing. Diabet Med 2009, 26:679-685.

21. Hamer M, Lavoie KL, Bacon SL: Taking up physical activity in later life and healthy ageing: the english longitudinal study of ageing. Br J Sports Med 2013. doi: 10.1136/bjsports-2013-092993. [Epub ahead of print].

22. Pulsford RM, Stamatakis E, Britton AR, Brunner EJ, Hillsdon MM: Sitting behavior and obesity: evidence from the Whitehall II study. Am J Prev Med 2013, 44:132-138.

\section{doi:10.1186/1471-2458-14-10}

Cite this article as: Hamer et al:: Watching sport on television, physical activity, and risk of obesity in older adults. BMC Public Health 2014 14:10.

\section{Submit your next manuscript to BioMed Central and take full advantage of:}

- Convenient online submission

- Thorough peer review

- No space constraints or color figure charges

- Immediate publication on acceptance

- Inclusion in PubMed, CAS, Scopus and Google Scholar

- Research which is freely available for redistribution 